\title{
Thesis summary
}

\section{THE EFFECT OF TWO DIFFERENT GRAZING TREATMENTS. ON SUBSEQUENT PASTURE RECOVERY}

\author{
(B.Agr.Sc. (Hons.) , Massey University)
}

\section{S. J. Rosie}

An established grass/clover pasture was subjected to two different grazing treatments in April-May 1976. The recovery of continuously and intermittently defoliated swards was compared over a 6-week recovery period.

Eight sequential harvests were carried out over the experimental period. Total dry matter yield, botanical composition, and some components of regrowth, in particular clover, were determined.

There was evidence of a period of negative growth, approximately 2 weeks, following defoliation. This suggests that the rate of pasture death and decay was greater than the corresponding growth rate.

The results obtained also suggest that the main contribution to regrowth of the grass species. comes from the production of new tillers rather than the growth of existing tillers. Similarly, an increase in the density of clover units was observed, rather than an increase in size and weight of existing components. 